\title{
The Effectiveness of Dialectical Behavior Therapy in Decreasing High Risk Behaviors Among Students Suffering From Attention Deficit / Hyperactivity Disorder
}

\author{
Nasser Sobhi Gharamaleki, ${ }^{1}$ Saeed Pourabdol, ${ }^{2,}{ }^{*}$ Ramin Saravani, ${ }^{3}$ and Shahzad Saravani ${ }^{4}$ \\ ${ }^{1}$ Department of Psychology, Faculty of Educational Sciences and Psychology, University of Mohaghegh Ardabili, Ardabil, Iran \\ ${ }^{2}$ Department of Psychology, Faculty of Human Sciences, Shahed University, Tehran, Iran \\ ${ }^{3}$ Department of Clinical Biochemistry, Cellular and Molecular Research Center, School of Medicine, Zahedan University of Medical Sciences, Zahedan, Iran \\ ${ }^{4}$ Department of Psychology, Faculty of Humanities, Islamic Azad University of Qom, Qom, Iran \\ "Corresponding author: Saeed Pourabdol, Department of Psychology, Faculty of Human Sciences, Shahed University, Tehran, Iran. E-mail: saeed.pourabdol@yahoo.com
}

Received 2016 February 14; Revised 2016 June 03; Accepted 2017 January 09.

\begin{abstract}
Background: Attention deficit/hyperactivity disorder is a kind of disorder that may lead to interpersonal, emotional, educational and domestic problems. Moreover, it may lead to high-risk behaviors among teenagers and this area of research is now a focus of attention for many researchers in order to find solution for its treatment and prevention.

Objectives: The aim of present study was to determine the effectiveness of dialectical behavior therapy on the decrease of high risk behaviors among students suffering from attention deficit/hyperactivity disorder.

Methods: This research was done experimentally and through designing pre-test and post-test and using control group. Research population included all male third-grade high school students suffering from attention deficit/hyperactivity disorder (case study: Ardabil city, 2015). Research sample included 40 male students suffering from attention deficit/hyperactivity disorder who were selected through multi-step cluster sampling and classified into two groups: experimental group ( $\mathrm{n}=20$ subjects)and control group ( $\mathrm{n}=20$ subjects). For data collection we used Iranian teenage risk-taking scale, Conner's Adult ADHD Rating Scale- Self report form and Subscale and diagnostic interview based on DSM-5. The data were analyzed by univariate analysis of covariance (ANCOVA) model in the SPSS software version 22.

Results: The results of univariate analysis of covariance showed that dialectical behavior therapy had been effective in decreasing high-risk behaviors $(\mathrm{P}<0 / 001)$. The data analysis had showed that there was a significant difference between high-risk behaviors of control and experiment groups in the post-test.

Conclusions: According to the findings training dialectical behavior is effective in controlling emotional behavior and in regulation of emotions; therefore, along with other therapeutic methods we can use this approach as an effective way to decrease psychological and behavioral problems mainly high risk behaviors of teenagers suffering from attention deficit/hyperactivity disorder.
\end{abstract}

Keywords: Attention Deficit / Hyperactivity Disorder, High-Risk Behavior, Dialectical Behavior Therapy

\section{Background}

Attention deficit / hyperactivity disorder (ADHD) is one of the common problems among children and teenagers who refer to psychiatrists and psychologists [1]. It is a behavioral pattern, which is sometimes prolonged up to adulthood and evolutionally it is emerged with a disproportionate degree of lack of attention, Impulsivity and hyperactivity [2]. The main attributes of ADHD is the continuous pattern of inattentiveness or hyperactivityImpulsivity, which is in contradiction to one's function and growth. For diagnosing symptoms of attention deficit/hyperactivity disorder such a behavior must be shown 6 months among children before 12 years old and 5 months among teenagers and adults. The common definition of ADHD includes 18 behavioral symptoms, which are divided into two 9-symptomed sets: attention deficit and hyperactivity-Impulsivity; and they are in turn divided into 3 subsets for ADHD: 1 . Attention deficit domination; 2. Hyperactivity-impulsivity domination; 3. A combination 1 and 2, which a complete syndrome. Studies in different societies show that about $5 \%$ of children and $2.5 \%$ of adults in different cultures are suffering from ADHD. In a normal population ADHD is more common among boys than girls and its ratios among children and adults are 2:1 and 1.6:1, respectively. Attention deficit as a main symptom emerges more among girls [3]. Such a disorder is along with other problems such as educational performance, weak relationship with family and friends, low psychic health and drug abuse at the lower ages [4]. In a research, Faraone and Biederman [5] study the record of educational failure and emotional problems such as anxiety and depression among teenagers with symptoms of atten- 
tion deficit/hyperactivity disorder. Research evidence indicates that attributes such as a degree of depression, anxiety and limited interpersonal relationships are among the attributes of students suffering from hyperactivity [6].

From among the effective factors that can affect different aspects of students suffering from ADHD and can be one of the consequences of this disorder, is high-risk behavior. High-risk behaviors are now considered as the behaviors that endanger health and welfare of teenagers, youths and other members of a society [7]. This behavior is divided into two groups: $1^{\text {st }}$ group are behaviors such as smoking, alcohol and drug abuse and high-risk and insecure sexual behaviors that endanger health and welfare of its doer [8] but $2^{\text {nd }}$ group are behaviors such as rubbery, aggression, escape from school and home that endanger others' health and welfare. Through the study of experimental history of this subject, one can clearly observe the impacts of such behaviors on job, educational and social performances. By alcohol and drug abuse, for example, besides psychological and physical damages and financial losses youths may experience, they endanger other people through accidents that claim the death of many people as the aftermath of such behaviors and this cost a lot for societies $[9,10]$. The results of different researches indicate that students with high-risk behavior are more intended to leave school, get lower marks at school or run away from school [11]. In their report about high-risk behaviors of American high school students in 2006, Eaton et al. showed that 30 days before conducting research subjects under study were involved in: dangerous driving as a result of drinking alcohol (9.9 percent), carrying gun (18.5\%) and committing suicide ( $8.4 \%$ ); moreover during 12 months before conducting research 35.9 percent of the subjects were involved in physical violence [12]. Furthermore, the results of different researches show that students suffering from ADHD have more high-risk behaviors, and experience alcohol abuse and eating disorders more than normal students [13-15]. In a research it is observed that there is negative relationship between high-risk and self-injurious behaviors of teenagers and their psychic and physical health [16].

One of the common therapeutic methods that might be of wide use in the area of treating behavioral disorders of teenagers and has been neglected is dialectical behavioral therapy (DBT). Dialectical behavioral therapy is a cognitive-behavioral approach, which is primarily developed for treating Borderline personality disorder (BPD). This approach has mixed the interventions related to cognitive, behavioral and supportive treatments (which are based on the principle of change) with the courses and techniques of eastern philosophy of Zen (which is based on the principle of acceptance); accordingly it has introduced four interventional parameters in this group ther- apeutic method [17]. The skills related to dialectical behavior therapy include distress tolerance, emotion regulation, core mindfulness, and interpersonal effectiveness [18]. The degree of people's endurance and resistance against negative psychological conditions and experiencing such condition is called distress tolerance [19]. Low distress tolerance may lead to impulsive behaviors and repression of discomfort and pain, but the increase in distress tolerance may play an important role in treating high-risk behaviors such as suicide [20]. Emotion regulation is referred people's ability to affect the kind, time and manner of experiencing and expressing emotion; moreover it is referred to a change in the duration or intensity of behavioral, experimental and bodily processes of emotion, which is done consciously or unconsciously through emotion regulation strategies [21]. Core mindfulness is a proficiency through which events sensed with less inconveniency at the present time. When we pay attention to the present time we are not involved in the past or future; while most psychological problems rooted from concentration on the past [22]. There is a positive and fixed relationship between social skills and all psychological indicators of welfare and positive relations with others [23]. Dialectical behavior therapy is an approach that combines client-centered empathy and acceptance with resolving cognitive-behavioral issues and training social skills. Surveying research literature indicate the capability of dialectical behavior therapy in decreasing psychological and behavioral disorders like high-risk behaviors of students suffering from attention deficit hyperactivity disorder. The results of research show that training cognitive-behavioral strategies decreases aggression, molestation and anger of boys suffering from attention deficit/hyperactivity disorder [24]. Other research findings indicate that employing strategies related to dialectical behavior therapy is effective in decreasing hyperactivity, impulsivity and aggression/riot, and in empowering socially acceptable behaviors, increasing social cognition, and improving relationship with peers [25]. Moreover, other research findings indicate that dialectical behavior therapy is effective in decreasing aggression and controlling rage among teenagers as well as increasing their social competence [26]. Some other researchers report its effectiveness in treating self-harm behaviors [27] and emotion regulation disorder [28] among students suffering from such disorders.

Behavioral and social problems caused by risky behavior and its consequences in social and education life and increases the likelihood of high-risk behavior in people with attention deficit/hyperactivity adds the necessity and significance of such researches. All in all the results of conducted researches indicate the effectiveness of dialectical behavior therapy in decreasing impulsivity, and self-harm 
behaviors, and in improving emotion regulation and some emotional issues such as depression, anxiety, anger and high-risk behaviors. The great bulk of researches support the effectiveness of this psychological intervention and all of them suggest the need for further researches, which shows the importance of conducting present research. On the other hand the study of this treatment model among people suffering from attention deficit/hyperactivity disorder has less been conducted in Iran and this research may fill some parts of this gap and the findings of this research, as a primary basis, can pave the way for future researches and for designing suitable interventions to decrease highrisk behaviors among such people.

\section{Objectives}

Hence, the aim of this study was to determine the effectiveness of dialectical behavior therapy on the decrease of high risk behaviors among students suffering from attention deficit / hyperactivity disorder.

\section{Methods}

This research was conducted experimentally through pre-test, post-test and control group. Research population includes all male junior high-school students suffering from attention deficit / hyperactivity disorder (case study: Ardabil city, 2015). After getting the required permission from Ardabil education with observing all ethical issues and explaining research goals to the subjects, we conducted the research: first through multi-step cluster sampling we selected 5 male high schools randomly, and then 3 classes were selected randomly from every selected high school. By explaining symptoms of attention deficit / hyperactivity disorder to the teachers we identified and selected those who showed symptoms of such disorders. Then for exact identification of ADHD students we used diagnostic interviews with regard to diagnostic and statistic manual of mental disorder (DSM-5) criteria and Connerss questionnaire. Finally 61 subjects were identified with such disorder among them 40 subjects were selected by simple random sampling as research sample who were randomly placed in experimental and control groups. The minimum number of sample must be 15 subjects in experimental researches [29], but for increasing external validity we selected 40 subjects (20 subjects for each subset) suffering from ADHD. The inclusion criteria for this study included having normal intelligence, lack of physical illness, male gender and Exclusion criteria included fatigue in training sessions and lack of cooperation in the students. For data collection following tools were used:
3.1. Structured Clinical Interview On the Basis of Symptoms in DSM-5

In this research for identifying symptoms of attention deficit / hyperactivity disorder we used structured clinical interview on the basis of symptoms described for ADHD in DSM-5 in this research reliability through Cronbach Alpha was to 0.84 .

\subsection{Conner's Adult ADHD Rating Scale-Self Report form and Subscale (CAARSS: $S$ )}

This scale is a form of self-report developed by Connerss, Erhardt and Sparrow [30]. Responses to the 26 items of this questionnaire were provided on a 4-point scale format ranging from 0 to 3 . The raw scores of this scale were turned into T-scores using suitable normative table (in this scale T-scores have average and standard deviation of 50 and 10, respectively). T-scores above 65 are significant clinically and T-scores above 80 not only show problem intensity and the pathology of that area but also indicate its malformation or exaggeration in symptoms [30]. This questionnaire is not normalized in Iran; but in their primary studies on 20 subjects Arabgol, Hayati and Hadide [31] have obtained its reliability through Cronbach Alpha (0.81) and its external validity is confirmed by three specialists in the related area. Questionnaire developers reported its reliability from 0.85 to 0.95 and its validity from 0.37 to 0.67 [30].in this research reliability through Cronbach Alpha was to 0.83 (Table 1 ).

\subsection{High-Risk Behavior Questionnaire}

In order to determine the prevalence rate and identify protective-incentive factors of risky behaviors, in the present study we used Mohammadi's high-risk behavior questionnaire [32]. This questionnaire has 38 questions. Each one is graded on the basis of the 5-degree Likert scale ("totally disagree" to "totally agree"). The scale includes 7 components (tendency to narcotics, tendency to alcohol, Tendency to cigarette smoking, tendency to violence, tendency to relationship and sexual behavior, tendency to heterosexual relationship, and tendency to dangerous driving). Psychometric properties in the standardized version of Mohammadi are promising concerning the difference diagnosis among the groups. Face validity of the questionnaire has been reported as equal to 0.77 by Rajabi and Cronbach's alpha coefficient as 0.67 . In this research Cronbach Alpha is 0.81 .

\subsection{Procedure}

After getting the required permission from Ardabil Education and informing and satisfying parents and teachers with observing all ethical issues and explaining re- 
Table 1. Sessions

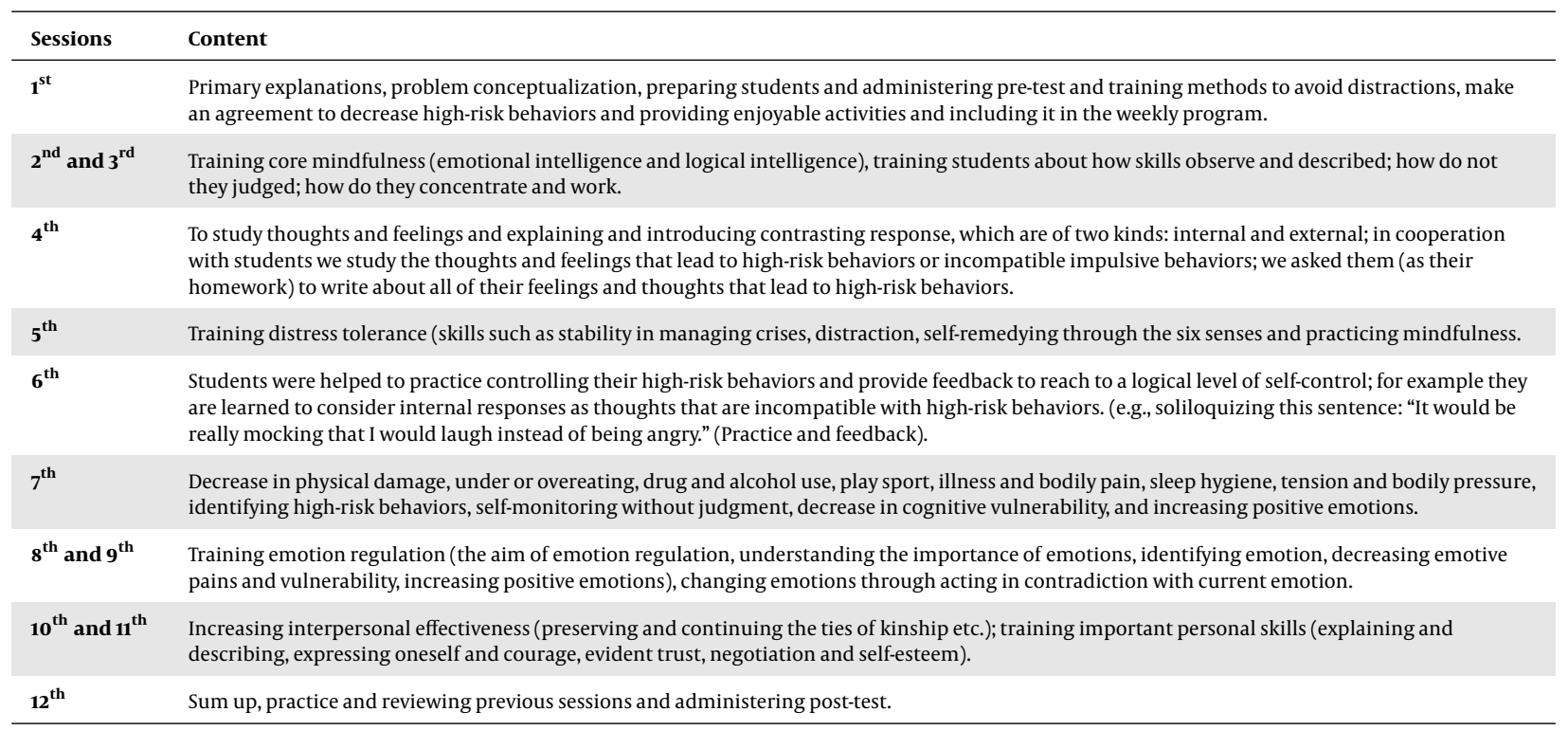

search goals to the subjects, they were attracted to the research. Then students fill Conner's scale and the subjects with high scores (2 standard deviations higher than average) were identified and interviewed clinically. Then students with symptoms of attention deficit / hyperactivity disorder were placed randomly in experimental and control groups. While justifying subjects and explaining research goals, we ask students to participate in the treatment course of this disorder. Before starting treatment course we administer a pre-test for both groups and ask subjects to fill in the questionnaires with regard to their attributes. It included twelve 60-minutes sessions once a week, which was held in a place determined by the education. During these sessions and two weeks after the course we test both groups through posttest; the obtained data were then analyzed using SPSS software and univariate analysis of covariance. Meanwhile, ensuring to protect data and preparing students mentally and psychologically to participate in the research is from among observed ethical issues of present research.

\section{Results}

Average and standard deviation of age for experimental group are 18.27 and 0.51 , respectively and those of control group are 18.20 and 0.49 respectively (with the ages ranging from 18 to 19). An independent-samples t-test was conducted to compare age in experimental and control group. There was not a significant difference in the scores for age $(\mathrm{P}=0.569)$ in the groups; these results suggest that groups (experimental and control) are equals in age.

As indicated in Table 2 average (and standard deviation) of pretest total score related to high risk behaviors of experiment group are 127.30 (and (12.06) and those of posttest for experiment group are 84.30 (and 13.25), respectively. Moreover, average (and standard deviation) of pretest total score related to high risk behaviors of control group are 135.55 (and (12.30) and those of posttest for control group are 138.55 (and 11.29), respectively.

Using a one-sample Kolmogorov-smirnov test For studying normal distribution of data between the two group, normality in the experimental group for Tendency to narcotics $(P=0.20)$, Tendency to alcohol $(P=0.45)$, Tendency to cigarette smoking $(P=0.20)$, Tendency to violence $(P=0.20)$, Dangerous relationship and sexual behavior $(P=0.20)$, Tendency to heterosexual relationship $(\mathrm{P}=0.13)$ and Tendency to dangerous driving $(\mathrm{P}=0.20)$ was obtained. Also in Control group normality for Tendency to narcotics $(P=0.07)$, Tendency to alcohol $(P=0.30)$, Tendency to cigarette smoking $(\mathrm{P}=0.16)$, Tendency to violence $(\mathrm{P}=0.43)$, Dangerous relationship and sexual behavior $(\mathrm{P}$ $=0.20)$, Tendency to heterosexual relationship $(\mathrm{P}=0.20)$ and Tendency to dangerous driving $(\mathrm{P}=0.92)$ was equal.

Before using parametric test of univariate analysis of covariance for observing its hypotheses we used tests of Levene's for each subvariable. On the basis of Levene's test, which was not significant for any variable the equality condition of variance/covariance is observed correctly (Table 3). 
Table 2. Average and Standard Deviation of High Risk Behaviors Among Normal Students and Those with Attention Deficit / Hyperactivity Disorder ${ }^{\mathrm{a}}$

\begin{tabular}{lccc}
\hline & \multicolumn{2}{c}{ Exprimental } & \multicolumn{2}{c}{ Contorol } \\
\cline { 2 - 4 } Dependent Variables & Pre-Test & Post-Test & Pre-Test \\
\hline Tendency to narcotics & $20.65 \pm 2.90$ & $13.70 \pm 2.61$ & $22 \pm 2.84$ \\
Tendency to alcohol & $16.45 \pm 2.85$ & $11.10 \pm 2.57$ & $18.25 \pm 2.19$ \\
\hline Tendency to cigarette smoking & $21.15 \pm 2.83$ & $12.90 \pm 2.96$ & $22.45 \pm 3.11$ \\
Tendency to violence & $17.80 \pm 2.26$ & $11.30 \pm 2.15$ & $17.60 \pm 3.06$ \\
\hline Dangerous relationship and sexual behavior & $16.70 \pm 2.25$ & $10.60 \pm 2.30$ & $18.10 \pm 2.51$ \\
\hline Tendency to heterosexual relationship & $20.70 \pm 3.34$ & $13.35 \pm 2.51$ & $22.85 \pm 3.06$ \\
\hline Tendency to dangerous driving & $13.95 \pm 1.98$ & $18.30 \pm 2.43$ & 2.45 \\
\hline Total score & $127.30 \pm 12.06$ & $9.10 \pm 1.58$ & $14.20 \pm 2.06$ \\
\hline
\end{tabular}

${ }^{\mathrm{a}}$ Value are expressed as Mean $\pm \mathrm{SD}$

Table 3. Results of Levene's Test of Equality of Error Variances

\begin{tabular}{|c|c|c|c|c|}
\hline Dependent Variable & $\mathbf{F}$ & dfi & df2 & Sig. \\
\hline Tendency to narcotics & 2.558 & 1 & 38 & 0.118 \\
\hline Tendency to alcohol & 1.393 & 1 & 38 & 0.245 \\
\hline Tendency to cigarette smoking & 0.020 & 1 & 38 & 0.887 \\
\hline Tendency to violence & 0.938 & 1 & 38 & 0.339 \\
\hline Tendency to heterosexual relationship & 5.360 & 1 & 38 & 0.26 \\
\hline Tendency to dangerous driving & 2.952 & 1 & 38 & 0.09 \\
\hline
\end{tabular}

As indicated in Table 4, the results of univariate analysis of covariance showed that after adjustment pre-test scores effects, there is a significant difference between average scores of tendency to narcotics with $(F=120.70)$, tendency to alcohol with $(\mathrm{F}=264.35)$, tendency to cigarette smoking with $(\mathrm{F}=102.84)$, tendency to violence with $(\mathrm{F}=$ 61.96), dangerous relationship and sexual behavior with ( $F$ $=75.23)$, tendency to heterosexual relationship with $(\mathrm{F}=$ 106.58) and tendency to dangerous driving with $(\mathrm{F}=222.88)$ between experiment group and control group $(\mathrm{P}<0.001)$. Hence it can be concluded that at the posttest level, dialectical behavior therapy will decrease high risk behaviors among students suffering from attention deficit / hyperactivity disorder (experiment group) in comparison to control group.

\section{Discussion}

The aim of this research was to study the effectiveness of dialectical behavior therapy in decreasing high-risk behaviors of students suffering from attention deficit/hyperactivity disorder. The results indicated that dialectical behavior therapy is of significant effect in decreasing high-risk behaviors of students suffering from attention deficit/hyperactivity disorder.

The findings were in line with findings of previous researches [24-28], which indicates the effectiveness of this therapeutic method in decreasing psychological, emotional and behavioral problems like high-risk behaviors. In defining the findings of this research it can be said that in dialectical behavior therapy the basis of change is acquiring skills and proficiencies and creating behavioral incentives, hence Linehan added therapeutic strategies to the treatment that is a reflection of acceptance and validating behavioral capacities and capabilities of current clients. Maintaining balance between acceptance and change is one of the dialectical principles of this approach. In this therapeutic approach, treatment consists of three parts: a) training skills and proficiencies; b) emphasis on motivating subjects and empowering skills; c) generalizing skills to real life and to the world outside of treatment sessions [33]. On the other hand dialectical behavior therapy with training skills such as failure tolerance, interpersonal 


\begin{tabular}{|c|c|c|c|c|c|c|}
\hline Dependent Variable & Source & SS & dF & MS & $\mathbf{F}$ & $\mathbf{P}$ \\
\hline \multirow{3}{*}{ Tendency to narcotics } & Pre-test & 5.59 & 1 & 5.59 & 0.96 & 0.33 \\
\hline & Group and pre-test & 5.74 & 1 & 5.74 & 0.98 & 0.32 \\
\hline & Group & 701.25 & 1 & 701.25 & 120.70 & 0.001 \\
\hline \multirow{3}{*}{ Tendency to alcohol } & Pre-test & 2.11 & 1 & 2.11 & 0.55 & 0.46 \\
\hline & Group and pre-test & 0.56 & 1 & 0.56 & 0.14 & 0.41 \\
\hline & Group & 1017.65 & 1 & 1017.65 & 264.35 & 0.001 \\
\hline \multirow{3}{*}{ Tendency to cigarette smoking } & Pre-test & 7.29 & 1 & 7.29 & 1.01 & 0.32 \\
\hline & Group and pre-test & 1.36 & 1 & 1.36 & 0.186 & 0.66 \\
\hline & Group & 740.09 & 1 & 740.09 & 102.84 & 0.001 \\
\hline \multirow{3}{*}{ Tendency to violence } & Pre-test & 1.87 & 1 & 1.87 & 0.26 & 0.61 \\
\hline & Group and pre-test & 7.56 & 1 & 7.56 & 1.06 & 0.31 \\
\hline & Group & 442.61 & 1 & 442.61 & 61.96 & 0.001 \\
\hline \multirow{3}{*}{$\begin{array}{l}\text { Dangerous relationship and sexual } \\
\text { behavior }\end{array}$} & Pre-test & 0.37 & 1 & 0.37 & 0.04 & 0.83 \\
\hline & Group and pre-test & 1.80 & 1 & 1.80 & 0.21 & 0.64 \\
\hline & Group & 604.37 & 1 & 604.37 & 75.23 & 0.001 \\
\hline \multirow{3}{*}{ Tendency to heterosexual relationship } & Pre-test & 9.30 & 1 & 9.30 & 0.83 & 0.36 \\
\hline & Group and pre-test & 6.82 & 1 & 6.82 & 0.60 & 0.44 \\
\hline & Group & 1186.49 & 1 & 1186.49 & 106.58 & 0.04 \\
\hline \multirow{3}{*}{ Tendency to dangerous driving } & Pre-test & 0.28 & 1 & 0.28 & 0.06 & 0.79 \\
\hline & Group and pre-test & 1.73 & 1 & 1.73 & 0.41 & 0.52 \\
\hline & Group & 918.44 & 1 & 918.44 & 222.88 & 0.001 \\
\hline
\end{tabular}

skills and emotion regulation and a combination of these 3 approaches through client-centered empathy and solving cognitive-behavioral problems can increase flexibility and provide new ways for problem solving and modify unpleasant conditions and high-risk behaviors. Moreover, through emotion regulation skills we help subjects to identify their feelings with more accuracy and then study every emotion without disappointment. Therefore, the aim of training dialectical behavior therapy through emotion regulation skills is to modify emotions without reactive, aggressive and high-risk behaviors [34]. Some skills such as ability to be aware of emotions, identifying and naming emotions, correct interpretation of bodily feelings related to emotions, perceiving emotional excitement, active modification of negative emotions for getting a better feeling, accepting negative feeling in its required time and tolerating negative emotion when it is unchangeable, facing with such conditions and not avoiding it in favor of major goals and enthusiastic support in distress times are among the skills of emotion regulation; studies show that there is a significant relationship between all of these skills and dif- ferent scales of psychological health as well as the decrease in high-risk behaviors among general and clinical populations [35]. On the other hand the effectiveness of dialectical behavior therapy in decreasing high-risk behaviors of students suffering from attention deficit/hyperactivity disorder can be justified in this way that some factors that may intensify impulsive behavior and molestation among such students include the lack of social and affective supports, low self-esteem, school problems, high-risk behaviors and temperamental disorders [34]. Therefore dialectical behavior therapy is employed as a supportive treatment and requires a strong mutual relationship between therapist and client of the treatment in which the therapist actively train the client how to have and improve compatible behaviors; hence such treatment can be effective in decreasing selfinjurious behaviors [36]. In fact this therapeutic method through training interpersonal skills presents a new tool for those who are under treatment (takers of treatment) to express their ideas and demand their needs, to set the limitations and to discuss the solutions. Hence such a treatment with training the above mentioned skills can support 
these students' relationships with others and help them to continue behaving in this manner [34]. On the other hand weak family interactions such as unstable upbringing of children based on punishment, cold and unfriendly parental attitude towards children, unstable and strict disciplinary rules, unsafe Attachment, insufficient parental control over children and the lack of positive relationship and expressing empathy [34] are considered as risk factors and indicators that generally expose children to highrisk behaviors [37]. Since these students have more impulsive and aggressive behaviors than their normal peers, they are not properly perceived and accepted by their parents and peers and this may lead to seclusion, loneliness and low self-esteem. And they find high-risk and impulsive behaviors as a temporary way to release their anger, which will of course worsen their interpersonal relations [38]. Therefore dialectical behavior therapy is a treatment with clear instructions, which uses behavioral techniques and includes dialectical techniques and principles (such as observation, meditation, confronting and contract or agreement). Training such behavioral techniques can be effective in decreasing high-risk and dangerous behaviors.

All in all with regard to the findings of this research using dialectical behavior therapy can help students suffering from ADHD to gain skills to solve interpersonal conflicts, to improve their relations with their parents and peers, to control negative emotions, to gain the ability to regulate and modify negative emotions, tensions and rage and finally to avoid high-risk behaviors. With regard to the importance adolescence and consequences of this period it is necessary for psychologists, psychiatrists and the related authorities to pay special attention to this therapeutic method and other methods of psychotherapy to prevent psychological, emotional and social problems. This research is limited to Ardabil city in Iran and it is hard to generalize the results to other regions. Moreover subjects include male high school students that make it difficult to generalize the results to other age groups and female students. Hence the need for future researches seems necessary in these areas. Moreover it is suggested to use this therapeutic method in clinical centers and for the treatment of other disorders such as pain, learning, social anxiety, oppositional defiant disorder and depression.

\section{Acknowledgments}

We thank all the personnel, at the students with Attention deficit /hyperactivity disorder, for their cooperation.

\section{Footnotes}

Authors' Contribution: All authors had equal role in design,work, statistical analysis and manuscript writing.

Funding/Support: This paper had been done by personal expenses.

\section{References}

1. Biederman J, Faraone SV. Attention-deficit hyperactivity disorder. The Lancet. 2005;366(9481):237-48. doi: 10.1016/s0140-6736(05)66915-2.

2. Gupta R, Kar BR. Development of attentional processes in ADHD and normal children. 2009 ;176:259-76. doi: 10.1016/s0079-6123(09)176148

3. Diagnostic and statistical manual of mentaldisorders. 5th ed. Washington: American Psychiatric Association; 2013.

4. Davids E, Gastpar M. Attention deficit hyperactivity disorder and borderline personality disorder. Prog Neuropsychopharmacol Biol Psychiatry. 2005;29(6):865-77. doi: 10.1016/j.pnpbp.2005.04.033. [PubMed: 15951086].

5. Faraone SV, Biederman J, Spencer T, Wilens T, Seidman LJ, Mick E, et al. Attention-deficit/hyperactivity disorder in adults: an overview. Biol Psychiatry. 2000;48(1):9-20. doi:10.1016/s0006-3223(00)00889-1.

6. Bennett DS, Sullivan MW, Lewis M. Neglected children, shameproneness, and depressive symptoms. Child Maltreat. 2010;15(4):30514. doi: $10.1177 / 1077559510379634$. [PubMed: 20724372].

7. Maher F. Risky behaviors in leisure's youth: procedures and patterns. JYouth Studies. 2004;6:118-43.

8. Zarei E. Relationship between parent childrearing practices and high risky behavior on basis of Cloninger's scale.J Shahid Sadoughi Univer Med Sci. 2010;18(3):220-4.

9. Bond J, Macdonald S, Cherpitel C, Borges G, Giesbrecht N. Alcohol and injuries. Emergency department studies in an international perspective. World Health Organization Geneva, Switzerland; 2009.

10. Malekshahi F, Moumannasab M. The effects of high risk behaviors prevention educational program on the knowledge end attitude of school health trainers in Khorram-Abad. J Lore Univer Med Sci. 2007;9(2):47-54.

11. Kodjo C, Auinger P, Ryan S. Prevalence of, and factors associated with, adolescent physical fighting while under the influence of alcohol or drugs. J Adolescent Health. 2004;35(4):11-6. doi: 10.1016/s1054139x(04)00062-X.

12. Eaton DK, Kann L, Kinchen S, Ross J, Hawkins J, Harris WA, et al. Youth risk behavior surveillance-United States, 2005. J Sch Health. 2006;76(7):353-72. doi: 10.1111/j.1746-1561.2006.00127.x. [PubMed: 16918870].

13. Fuemmeler BF, Kollins SH, McClernon FJ. Attention deficit hyperactivity disorder symptoms predict nicotine dependence and progression to regular smoking from adolescence to young adulthood. J Pediatr Psychol. 2007;32(10):1203-13. doi: 10.1093/jpepsy/jsm051. [PubMed: 17602186].

14. Farhat T. Stigma, Obesity and Adolescent Risk Behaviors: Current Research and Future Directions. Curr Opin Psychol. 2015;5:56-66. doi: 10.1016/j.copsyc.2015.03.021. [PubMed: 26086032].

15. Baumann S, Gaertner B, Schnuerer I, Haberecht K, John U, FreyerAdam J. Belief incongruence and the intention-behavior gap in persons with at-risk alcohol use. Addict Behav. 2015;48:5-11. doi: 10.1016/j.addbeh.2015.04.007. [PubMed: 25930010].

16. Oktan V. An investigation of problematic internet use among adolescents in terms of self-injurious and risk-taking behavior. Child Youth Serv Rev. 2015;52:63-7. doi:10.1016/j.childyouth.2015.03.009.

17. Linehan M, Dexter-Mazze E. 136. ;2008. pp. 365-462..Dialectical Behavior Therapy for Borderline Personslity Disorder. 
18. Alilou M, Sharifi MA. Dialectical Behavior Therapy for Borderline Personality Disorder 2011. Available from: http://counseling.au.ac.ir.

19. Simons JS, Gaher RM. The Distress Tolerance Scale: Development and Validation of a Self-Report Measure. Motivation and Emotion. 2005;29(2):83-102. doi:10.1007/s11031-005-7955-3.

20. Linehan MM, Heard HL, Armstrong HE. Naturalistic follow-up of a behavioral treatment for chronically parasuicidal borderline patients. Arch Gen Psychiatry. 1993;50(12):971-4. [PubMed: 8250683].

21. Gross JJ, Thompson RA. ; 2007. Emotion regulation: Conceptual foundations.

22. Kabat-Zinn J. Mindfulness-based interventions in context: Past, present, and future. Clinical Psychology: Sci Prac. 2003;10(2):144-56. doi: 10.1093/clipsy.bpg016.

23. Segrin C, Taylor M. Positive interpersonal relationships mediate the association between social skills and psychological well-being. Pers Indiv Differ. 2007;43(4):637-46. doi:10.1016/j.paid.2007.01.017.

24. Sukhodolsky DG, Solomon RM, Perine J. Cognitive- Behavioral, Angef control. Intervention for Elementary School Children: A Treatment outcome study. J Am Acad Child Adolesc psychiatry. 2008;10(2):159-70.

25. Dallnic A, Smith SW, Brank EM, Penfield RD. Classroom- based dialectical behavior therapy intervention to prevent aggression: Efficiency and social validity. J Scl Psychology. 2012;44(1):123-39.

26. Frazier SN, Vela J. Dialectical behavior therapy for the treatment of anger and aggressive behavior: A review. Aggre Violent Behav. 2014;19(2):156-63. doi: 10.1016/j.avb.2014.02.001.

27. Gibson J, Booth R, Davenport J, Keogh K, Owens T. Dialectical behaviour therapy-informed skills training for deliberate self-harm: a controlled trial with 3-month follow-up data. Behav Res Ther. 2014;60:8-14. doi: 10.1016/j.brat.2014.06.007. [PubMed: 25036538].

28. Neacsiu AD, Eberle JW, Kramer R, Wiesmann T, Linehan MM. Dialectical behavior therapy skills for transdiagnostic emotion dysregulation: a pilot randomized controlled trial. Behav Res Ther. 2014;59:40-
51. doi: 10.1016/j.brat.2014.05.005. [PubMed: 24974307].

29. Delavar A. Theoretical and Practical Research Foundations in the Humanities and Social Sciences. Tehran: Roshd;; 2011.

30. Connerss CK, Erhardt D, Sparrow E. Connerss adlt adhd rating scales (CAARS) tech nical manual. Multi Health Systems. ;14(4):431-7.

31. Arabghol F, Hayati M, Hadideh M. Prevalence of attention deficit/ hyperactivity disorder in the group of students. Inst Cogn Sci Stud. 2004;6(2):73-8.

32. Mohammadi A. Z. , Abadi AZ. Simultaneous occurrence of high-risk behaviors among high school adolescents in tehran [In Persian].JFam Res. 2006;3(13):87-9.

33. Bohus M PESCHBLMRT:. Effectiveness of inpatient dialectical behavior therapy for borderline personality disorder: A controll trial. Behav Res Th. 2004;42(5):487-99.

34. Lengua LJ, Honorado E, Bush NR. Contextual risk and parenting as predictors of effortful control and social competence in preschool children. J Appl Dev Psychol. 2007;28(1):40-55. doi: 10.1016/j.appdev.2006.10.001. [PubMed: 21687825].

35. Berking M, Margraf M, Ebert D, Wupperman P, Hofmann SG, Junghanns K. Deficits in emotion-regulation skills predict alcohol use during and after cognitive-behavioral therapy for alcohol dependence. $J$ Consult Clin Psychol. 2011;79(3):307-18. doi: 10.1037/a0023421. [PubMed: 21534653].

36. DiGiorgio KE, Glass CR, Arnkoff DB. Therapists' use of dbt: A survey study of clinical practice. Cogn and Beha Prac. 2010;17(2):213-21. doi: 10.1016/j.cbpra.2009.06.003.

37. Webster-Stratton C. Aggression in young children services proven to be effective in reducing aggression. Rev ed. 2003;14(2):108-18.

38. Ben-Porath DD. Dialectical behavior therapy applied to parent skills training: Adjunctive treatment for parents with difficulties in affect regulation. Cogn Behav Pract. 2010;17(4):458-65. doi: 10.1016/j.cbpra.2009.07.005. 